\title{
Investigation of the role of gas hydrates in continental slope stability west of Fiordland, New Zealand
}

\author{
GARETH J. CRUTCHLEY \\ ANDREW R. GORMAN \\ MIKO FOHRMANN \\ Department of Geology \\ University of Otago \\ PO Box 56 \\ Dunedin 9054, New Zealand
}

\begin{abstract}
Sediment weakening due to increased local pore fluid pressure is interpreted to be the cause of a submarine landslide that has been seismically imaged off the southwest coast of New Zealand. Data show a distinct and continuous bottom-simulating reflection (BSR) - a seismic phenomena indicative of the presence of marine gas hydrate- below the continental shelf from water depths of c. $2400 \mathrm{~m}$ to c. $750 \mathrm{~m}$, where it intersects the seafloor. Excess pore fluid pressure (EPP) generated in a free gas zone below the base of gas hydrate stability is interpreted as being a major factor in the slope's destabilisation. Representative sediment strength characteristics have been applied to limit-equilibrium methods of slope stability analysis with respect to the Mohr-Coulomb failure criterion to develop an understanding of the feature's sensitivity to EPP. EPP has been modelled with representative material properties (internal angle of friction, bulk soil unit weight and cohesion) to show the considerable effect it has on stability. The best estimate of average EPP being solely responsible for failure is $1700 \mathrm{kPa}$, assuming a perfectly elastic body above a pre-defined failure surface in a static environment.
\end{abstract}

Keywords gas hydrate; excess pore fluid pressure; submarine slope stability; marine seismic reflection

\section{INTRODUCTION}

The basis of this study is a previously unpublished, three-fold seismic reflection line acquired off the coast of Fiordland, southwest of New Zealand, in 1993 (Delteil et al. 1995) (Fig. 1). Seismic indications of gas hydrates have been observed previously on several datasets collected in this region, where they have assisted in modelling the heat flow regime (Townend 1997), and have been mapped to determine the extent of the gas hydrate province (Fohrmann et al. in press). One of these lines, Geodynz-sud Line 61c, shows an apparent seafloor outcrop of the base of a marine gas hydrate layer (Fig. 2). This seismic image is one of the best examples of such a phenomenon yet to be published (cf. Tréhu et al.

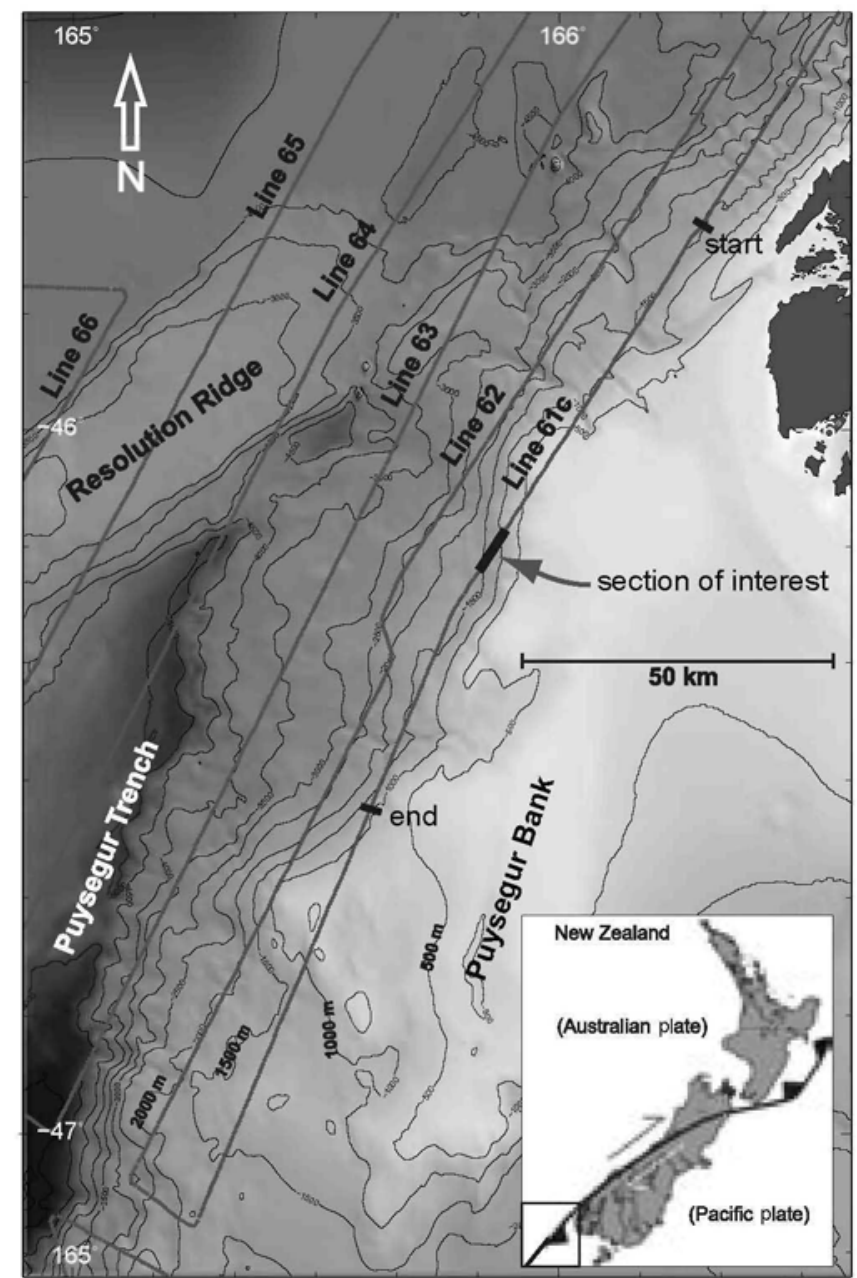

Fig. 1 Location map with inset map of New Zealand for reference. Labelled seismic lines show the distribution of the Geodynz-sud survey (1993). The start and end of segment "c" of line 61 (line 61c) are annotated, as well as the particular section of line $61 \mathrm{c}$ that is of interest to this study (Fig. 2). Prominent bathymetric features west of Fiordland are also labelled: Resolution Ridge, Puysegur Trench, and Puysegur Bank.

1995). Down dip from this outcrop, we interpret a significant submarine landslide, associated with the base of the gas hydrate system.

Submarine landslides are global phenomena that can occur on slopes that may be considerably less inclined than their terrestrial equivalents due to the presence of excess water (Hampton et al. 1996). They can displace huge amounts of material over great distances (e.g., the Storegga slide of Norway had a total run-out distance of c. $800 \mathrm{~km}$, with a total displaced volume of sediments estimated to be in the order of $5500 \mathrm{~km}^{3}$ ) (Bouriak et al. 2000). Slope failures occur when the downslope driving forces due to gravity and other factors exceed the resisting forces that are inherited from the sediment 


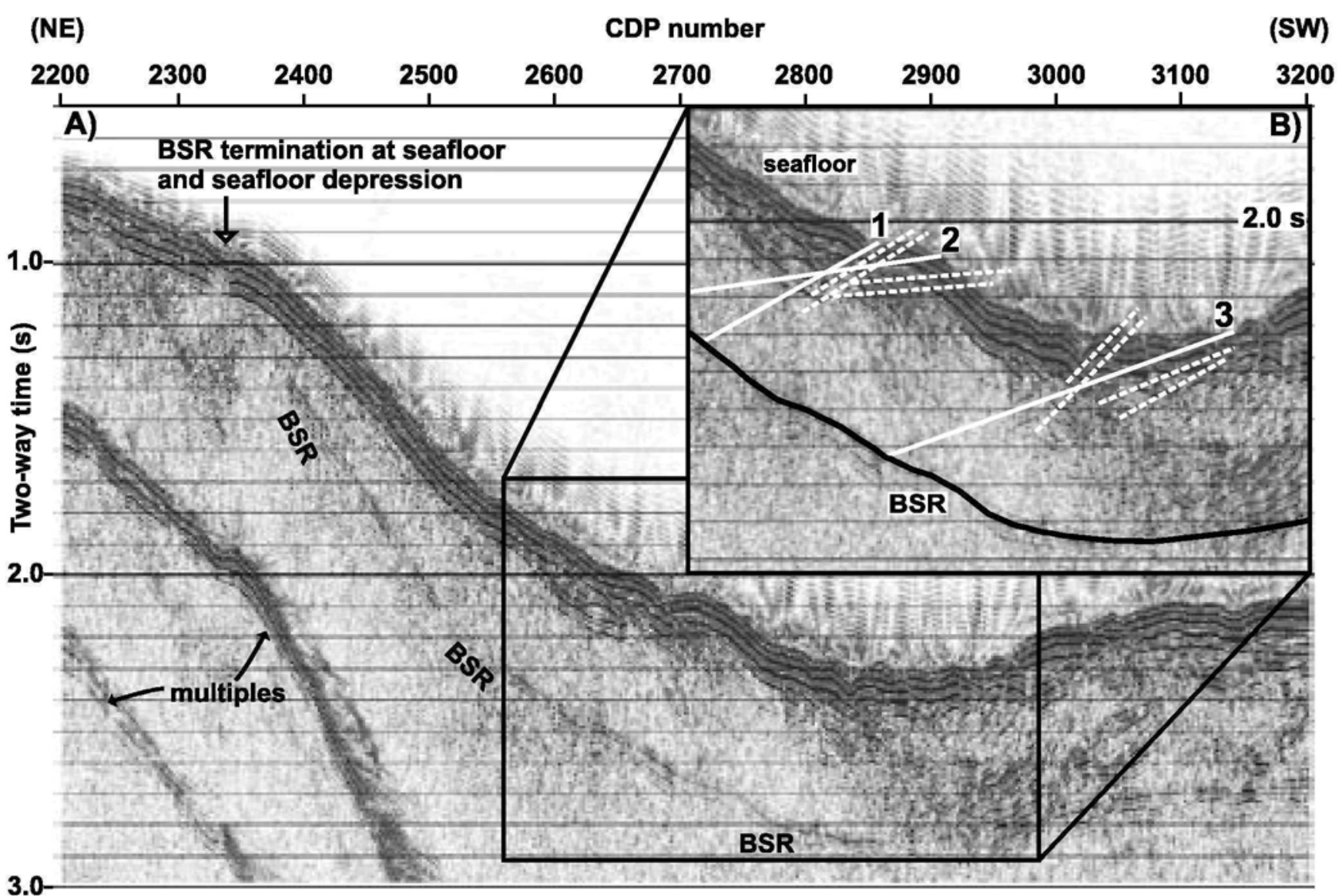

Fig. 2 A, Post-stack time-migrated data spanning the CDP range 2200-3200 (CDP spacing is $25 \mathrm{~m}$ ). The bottom-simulating reflection (BSR) and its termination at the seafloor, at a TWT (two-way time) of c. $1.0 \mathrm{~s}$, is shown. B, Interpretation near the toe of the slope failure. Disrupted bedding and hummocky bathymetry suggest that failure may have propagated from the BSR (delineated by the solid black line) to the seafloor. Possible failure surfaces linking the BSR to the seafloor are annotated as broken white lines and solid white lines. The surfaces delineated by the solid white lines (numbered 1-3) were selected for use in follow-up slope stability analysis. For future reference, they are referred to as "return-shears".

strength. It is from this notion that the definition of the factor of safety is derived (Bishop 1955). The expression for the factor of safety, $F$, is given by the ratio of the available shear strength, $\tau_{f}$ to the mobilised shear stress, $\tau$, $F=\frac{\tau_{f}}{\tau}$.

Slopes fail when $\tau$ equals or exceeds $\tau_{f}$ (i.e., $F \leq 1$ ). $\tau_{f}$ is derived from the Mohr-Coulomb failure criterion (Eqn 2), an expression that accounts for various strength parameters in a particular sediment,

$\tau_{f}=c+\sigma_{n}{ }^{\prime} \tan \phi$,

where, $c$ is cohesion (in Pa), $\sigma_{n}{ }^{\prime}$ is effective normal stress (in $\mathrm{Pa}$ ), and $\phi$ is internal angle of friction (in degrees).

The association between gas hydrates and submarine slope failure has been widely documented (e.g., Carpenter 1981; Field \& Barber 1993; Popenoe et al. 1993; Bouriak et al. 2000). Gas hydrates, ice-like clathrate compounds consisting of natural gas (usually methane) enclosed in a regular framework of water molecules, have been found to be a significant constituent of seafloor sediment in many continental shelf-slope environments around the world (Kvenvolden 1988; Buffett 2000). Examples of coincident gas hydrate distribution and slope failure include: the Cape Fear slide on the continental slope and rise southeast of Cape Fear, North Carolina (Popenoe et al. 1993), the Storegga slide on the continental slope off the coast of western Norway, extending out into the Norwegian Basin (Bouriak et al. 2000), and the Humboldt slide zone near the Mendacino triple junction on the Northern California continental margin (Field \& Barber 1993). Dissociation of gas hydrate at the base of the gas hydrate stability zone (GHSZ), in response to a change in the physical environment (i.e., temperature and/or pressure regime), can liberate excess gas and elevate the local pore fluid pressure in the sediment (Hornbach et al. 2003, 2004). An example of such an environmental shift responsible for gas hydrate dissociation is represented diagrammatically in Fig. 3. The increase in pore fluid pressure has the effect of decreasing the effective normal stress on any assumed failure surface, so that less shear stress is required to initiate failure. Whether free gas liberation by gas hydrate dissociation can singularly cause a landslide, rather than just being a contributing load or the final trigger, is dependent on various factors. These include rate of dissociation, sediment permeability, depth below sea level, and depth below the seafloor (Xu \& Germanovich 2006).

This study provides a further example of the association of gas hydrate systems with submarine slope instability. The aim of the study is to investigate the relationship between localised excess pore fluid pressure, generated by gas hydrate dissociation, and the observed slope failure. The investigations are facilitated by limit equilibrium slope stability modelling. 


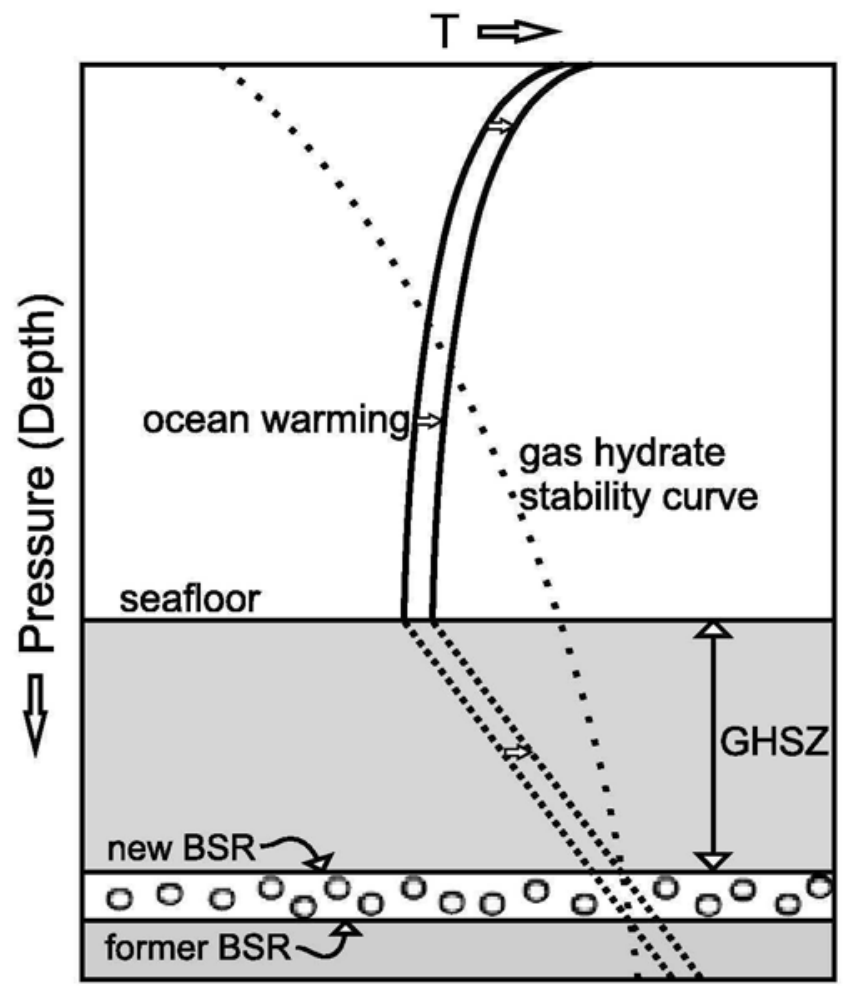

Fig.3 Schematic diagram showing how a particular environmental shift (increased ocean temperature) causes gas hydrate dissociation at the base of the gas hydrate stability zone. The gas hydrate phase boundary (sparse dotted line) is overlain on the thermal gradients (hydrothermal gradient above the seafloor, geothermal gradient below the seafloor). Gas hydrate is stable to the left of the phase boundary and to the right of the thermal gradients. The ocean warming is shown by a right-shift in the hydrothermal gradient, and consequently the geothermal gradient. BSR, bottom-simulating reflection.

\section{GEOLOGY OF THE FIORDLAND CONTINENTAL MARGIN}

New Zealand lies along the complex, obliquely converging plate boundary between the Australian plate on the west and the Pacific plate on the east. In the area relevant to this study, off the coast of Fiordland and south to the Puysegur Trench (Fig. 1), the Australian plate obliquely subducts beneath the Pacific plate (Davey \& Smith 1983; Delteil et al. 1996; Lamarche et al. 1997).

The geomorphology of the seafloor in this area (Fig. 1) is dominated by: (1) Resolution Ridge - a large, $2250 \mathrm{~m}$ high, northeast-trending massif on the Australian plate (Delteil et al. 1996) that is covered on the tops and sides by thick sedimentary sequences (200-1200 m on the top; Wood et al. 2000), and (2) the Puysegur Trench-a bathymetric low associated with oblique subduction of the Australian plate under the Pacific plate.

Resolution Ridge is just one of a series of right-stepping en echelon ridges that are oblique to the plate boundary (Delteil et al. 1996). It represents the western rift margin that was created following the initiation of spreading in the southeastern Tasman Sea from c. $45 \mathrm{Ma}$ (Sutherland 1995). The $5200 \mathrm{~m}$ deep Puysegur Trench is separated from the shallower Fiordland Basin to the north (not included in Fig. 1) by a saddle that owes its existence to the junction between Resolution Ridge and the continental slope to the east (Delteil et al. 1996). The specific area of interest in this study is slightly to the west of Puysegur Bank, in a more steeply dipping part of the Pacific continental crust (the continental slope).

Wood et al. (2000) have partially constrained the geology of the offshore Fiordland area by integrating regional offshore seismic data with onshore geological observations. No offshore well cores or seafloor samples have been taken from the area to provide direct observations. The youngest sediments, up to several kilometres thick in some places, are most likely to be late Miocene-Pleistocene clastics derived from tectonic uplift of the South Westland and Fiordland regions. In the Puysegur Trench, this sequence (referred to as Unit 4 in Wood et al. 2000) is less voluminous than it is to the north off Fiordland because Resolution Ridge has acted as a barrier to the transport of sediment (Wood et al. 2000). No constraints can be made regarding, (1) sediment assemblage properties such as grain size, grain shape, and sorting, and (2) sediment strength properties such as internal angle of friction, bulk unit weight, and cohesion. Typical sediment strength properties of continental margins need to be adopted from other studies (e.g., Lee \& Edwards 1986; Schwab \& Lee 1988; Barnes 2000) for use in the limit equilibrium slope stability modelling.

The oblique compressional tectonic setting of the offshore Fiordland area encourages enhanced fluid flow, and is host to a significant gas hydrate province (Fohrmann et al. in press). Dissociation of gas hydrates at the base of the GHSZ has the potential to be a slide trigger (Xu \& Germanovich 2006), especially considering that fluids are likely to be variably overpressured in response to sediment compaction and porosity loss, a common process associated with convergent margins (e.g., Screaton \& Saffer 2005).

\section{DATA PROCESSING AND INTERPRETATION}

The seismic data used in this study were acquired during the RV Atalante Geodynz-sud cruise in 1993. The acquisition system comprised two $75 \mathrm{in}^{3} \mathrm{GI}$ air guns and a six-channel streamer with a $50 \mathrm{~m}$ group spacing yielding three-fold coverage (Delteil et al. 1995, 1996; Lebrun et al. 2000). Our processing included application of the geometry, correction for spherical divergence, removal of normal moveout (NMO), and post stack time-domain migration and time-domain filtering that focused on the shallowest geological units. Lowfold and short offsets made conventional velocity analysis difficult, so the NMO velocity function was set to $1500 \mathrm{~m} / \mathrm{s}$ at the seafloor, arbitrarily increasing to $2000 \mathrm{~m} / \mathrm{s}$ at $2 \mathrm{~s}$ TWT (two-way time) below the seafloor.

Swath bathymetry data were also acquired during the 1993 Geodynz-sud cruise. These data have been used to produce the bathymetry map of Fig. 1. Unfortunately, the resolution of the data is not high enough to reveal further evidence of seafloor disruption.

Seismic data show the convergence of a dipping reflection with the inclined seafloor slope. The reflecting horizon is interpreted to be a bottom-simulating reflection (BSR) resulting from a change in elastic properties between an upper sediment layer (which may host gas hydrate but no free gas) and a lower sediment layer (which may contain free gas as bubbles and is free of gas hydrate). A noticeable depression in the region where the BSR intersects the seafloor, as well as hummocky bathymetry and disrupted bedding in the sediments near 

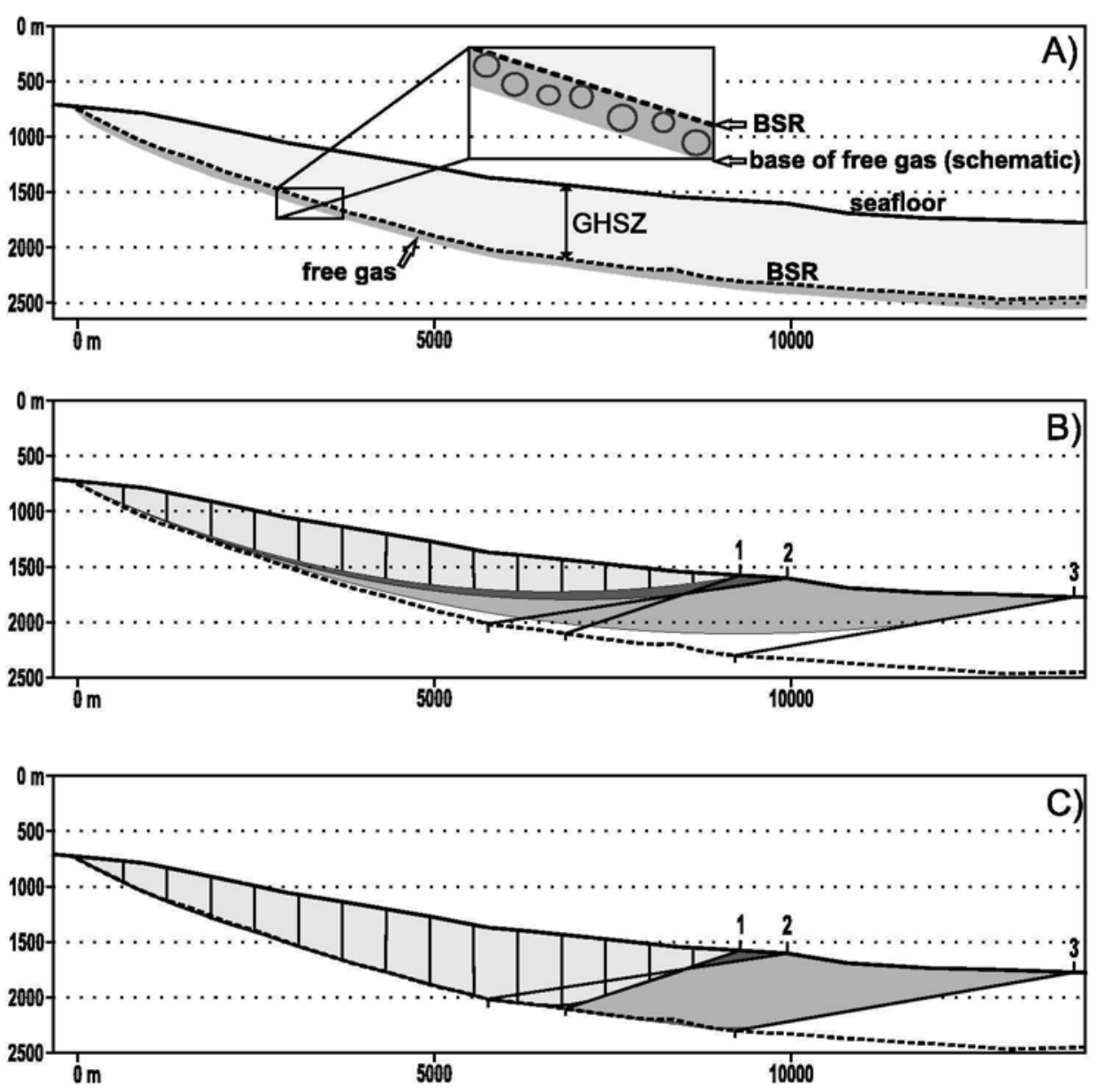

Fig. 4 Figures showing the landslide dimensions with an exaggerated vertical scale. The vertical scale is exaggerated in these figures so that the proposed failure surfaces in (B) and (C) can be seen more easily. A large-scale 1:1 section was used for inscribing failure surfaces, measuring angles, and measuring slice widths and depths - requirements for the slope stability analysis. A, Depth section of the seafloor and the bottomsimulating reflection (BSR) (as labelled). A schematic representation of the interpreted free gas zone (formed by uplift of the base of the gas hydrate stability zone) is also shown. B, Return-shears linking the BSR to the seafloor $(1,2$, and 3$)$, as identified in Fig. 2B, and the three circular failure surfaces that have been fitted to them and the BSR. The division of circular surface 1 into 15 vertical slices is also shown. C, Return-shears linking the BSR to the seafloor (1,2, and 3$)$, as identified in Fig. 3, and the three non-circular failure surfaces that have been fitted to them and the BSR. The division of non-circular surface 1 into 15 vertical slices is also shown. where the seafloor flattens out to subhorizontal, suggests there has been significant mass wasting in the area - extending almost $16 \mathrm{~km}$ on line 61c (Fig. 2). The coincidence of the BSR with the slope failure is strong evidence for an association with the gas hydrate system.

The dominant propagation direction of the slide cannot be constrained from the seismic and bathymetry data. The resolution of bathymetry data is too low to reveal a headwall scarp, and the seismic line is not likely to have been shot (by chance) parallel to the propagation direction. The orientation of the line is oblique to bathymetry contours in the region (Fig. 1), suggesting that it may also be oblique to the propagation direction. The depression on the seafloor (Fig. 2) could be part of the headwall scarp but it could also just be a sidewall scarp.

\section{LIMIT-EQUILIBRIUM SLOPE STABILITY ANALYSIS}

\section{Background}

Modelling presented in this study was based on the destabilising effect produced by the accumulation of excess (suprahydrostatic) pore fluid pressure (EPP) within a layer hosting free gas beneath the gas hydrate layer. A simplified 2D scenario was adopted, whereby slide propagation direction is assumed parallel to the seismic line. The analyses employed were limitequilibrium methods, which assume failure of a perfectly elastic body above a pre-defined failure surface in a static environment. The aim was to provide some quantification of EPP responsible for the observed slope failure. The application was an example of postulating a failure surface from pre-determined geometry and working backwards (under reasonable assumptions of sediment strength) to determine a level of EPP required to reduce the slope's factor of safety to 1 . This method assumes that the required EPP distribution existed at the time of failure. Representative sediment strength parameters adopted from other studies (Lee \& Edwards 1986; Schwab \& Lee 1988; Barnes 2000) were: internal angle of friction, $\phi=32^{\circ}$, bulk unit weight, $\gamma=18 \mathrm{kN}$, and cohesion, $c=0 \mathrm{~Pa}$. By adopting cohesion as $0 \mathrm{~Pa}$, the modelled EPP estimates are minima since it is likely that at least some minor cohesion exists in the sediment, particularly where the BSR is well below the seafloor.

\section{Selecting failure surfaces}

Failure surfaces used for the analysis were selected to be approximately coincident with the BSR in the upper parts of the slope, and with possible shear surfaces close to where the slope flattens out to subhorizontal. These shear surfaces were assumed to be feasible structures along which displacement was linked from the BSR back to the seafloor. For future reference, the shear surfaces herein are termed "return-shears". They are identified from what can be interpreted as disrupted bedding in the GHSZ and also from anomalous breaks in the bathymetry (Fig. 2B). Three possible shear surfaces selected for modelling are annotated as white lines in Fig. 2B. 
Fig.5 Comparison of the stability of non-circular and circular surfaces 1,2 , and 3 , as a function of increasing basal pore fluid factor $\mu$. Excess pore fluid pressure (EPP) distribution was modelled only on slice bases in close proximity to the bottom-simulating reflection (BSR) (the first method of modellingEPP distribution). Non-circular surface 1 is the least stable of all surfaces and is unstable above a $\mu$ of 0.85 .

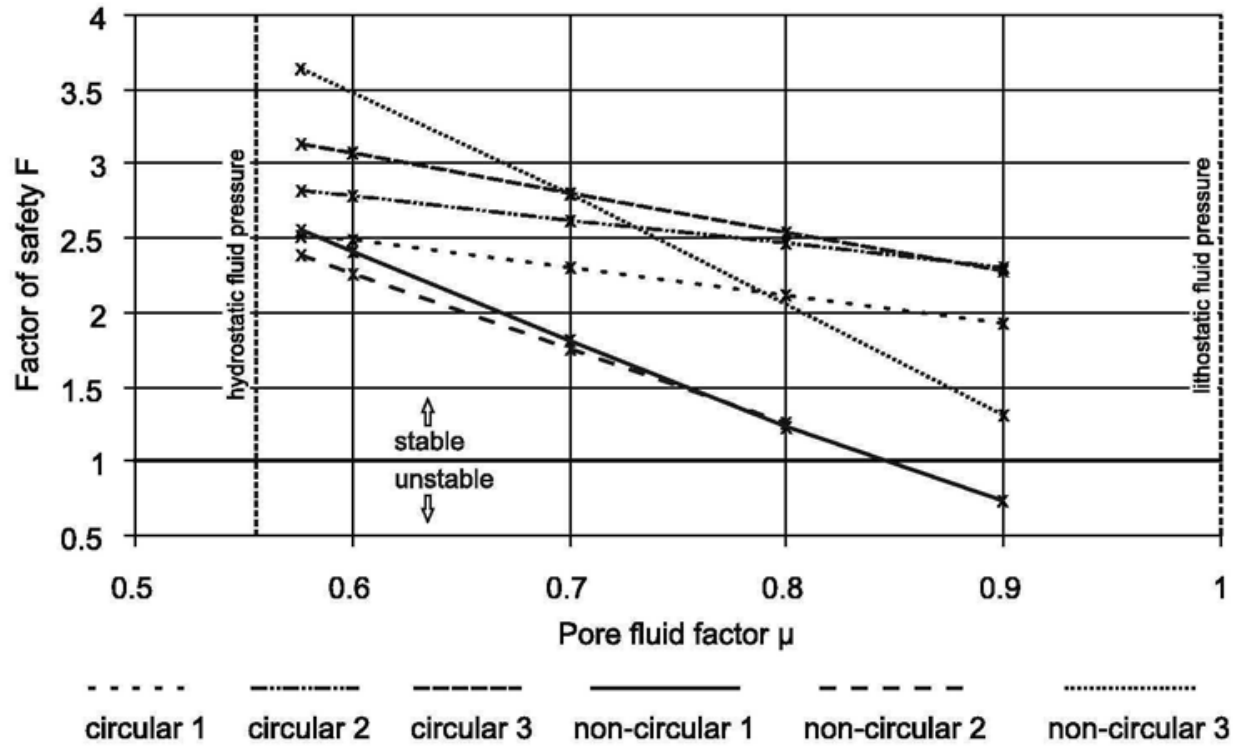

\section{Geometry}

The geometry of the slope failure was constrained by the seismic data, following the assumption of $2 \mathrm{D}$ slide propagation parallel to the section. A depth section was constructed from the seismic data using a P-wave velocity through sea water of $1500 \mathrm{~m} / \mathrm{s}$ and a P-wave velocity through partially gas-hydrate-saturated sediment of $1700 \mathrm{~m} / \mathrm{s}$ (Fig. 4A). The average velocity through the partially gas-hydrate-saturated sediment was inferred from other work (e.g., Lee et al. 1996). Twenty-six points along the horizontal axis have been used to define the geometry of the seafloor and the BSR, from the top of the failure (left hand side) to an arbitrary point past the end of the failure (right hand side). A schematic representation of the free gas layer beneath the gas hydrate layer is included in Fig. 4A.

Both circular and non-circular techniques were employed, using Bishop's simplified method and Spencer's method, respectively (Bishop 1955; Spencer 1967). Limit-equilibrium methods such as these require that a perfectly elastic body be fitted to the failed mass. This body is subsequently divided up into a series of vertical slices (15 in this case) that can be evaluated with respect to the driving and resisting forces acting on them. Circular failure surfaces (Fig. 4B) do not approximate the real geometry of the slide nearly as well as non-circular surfaces (Fig. 4C), making the circular method a more crude form of analysis. The advantage of the noncircular method is that the shape of the BSR can be closely followed down to one of the interpreted shear surfaces, rather than just being a circular approximation.

\section{Modelling}

The modelling was carried out with the use of Microsoft Excel spreadsheets and with TSLOPE software developed by Tagasoft. The distribution of EPP along the slip surface was modelled in two different ways. The first method involved limiting EPP to the part of the slip surface in close proximity to the BSR. This scenario assumed EPP to be localised at the base of the GHSZ and not along the return shears (Fig. 2B) that link the BSR to the seafloor. The second method involved modelling EPP over the entire slip surface, under the assumption that EPP was mobilised along the return shears as well as the BSR.

The amount of EPP was initially modelled by assuming the same constant pore fluid factor $\mu$ (the ratio of pore fluid pressure to lithostatic fluid pressure) at the base of each slice. This method offered a quick and simple way to compare stability of the different modelled failure surfaces (Fig. 5).

A more realistic method was then applied to non-circular surface 1 by introducing an EPP variation that depended on the depth of each slice base below sea level. The degree to which a given quantity of liberated gas can expand and contribute to EPP depends on the ambient confining pressure and temperature conditions, which vary with depth. This effect is most simply modelled by assuming that all EPP is due to liberated gas (ignoring the effect of liberated water), and by approximating the behaviour of the gas as ideal.

To reduce the factor of safety of the entire surface to 1 , a value of EPP was selected for the base of the shallowest slice, and the corresponding values for all other slice bases were resolved under the approximation of ideal gas behaviour. They were resolved by adopting reasonable thermal and pressure gradients through the overlying water and sediments. The temperature at the seafloor was assumed to be constant at $273^{\circ} \mathrm{K}$, the geothermal gradient adopted was $25^{\circ} \mathrm{K} / \mathrm{km}$, the density of water was taken as $1000 \mathrm{~kg} / \mathrm{m}^{3}$, the bulk density of the sediment was taken as $1800 \mathrm{~kg} / \mathrm{m}^{3}$, and a hydrostatic fluid pressure gradient between the seafloor and the bases of the slices was assumed. The value of EPP on the base of the shallowest slice was selected by iteratively calculating the factor of safety for the entire surface so that it converged to 1 .

\section{RESULTS}

Under the first modelling scenario of EPP distribution (EPP modelled just along the part of the slip surface in close proximity to BSR), the non-circular surfaces were significantly less stable than circular surfaces (Fig. 5). This was due to a greater proportion of slice bases being in close proximity to 


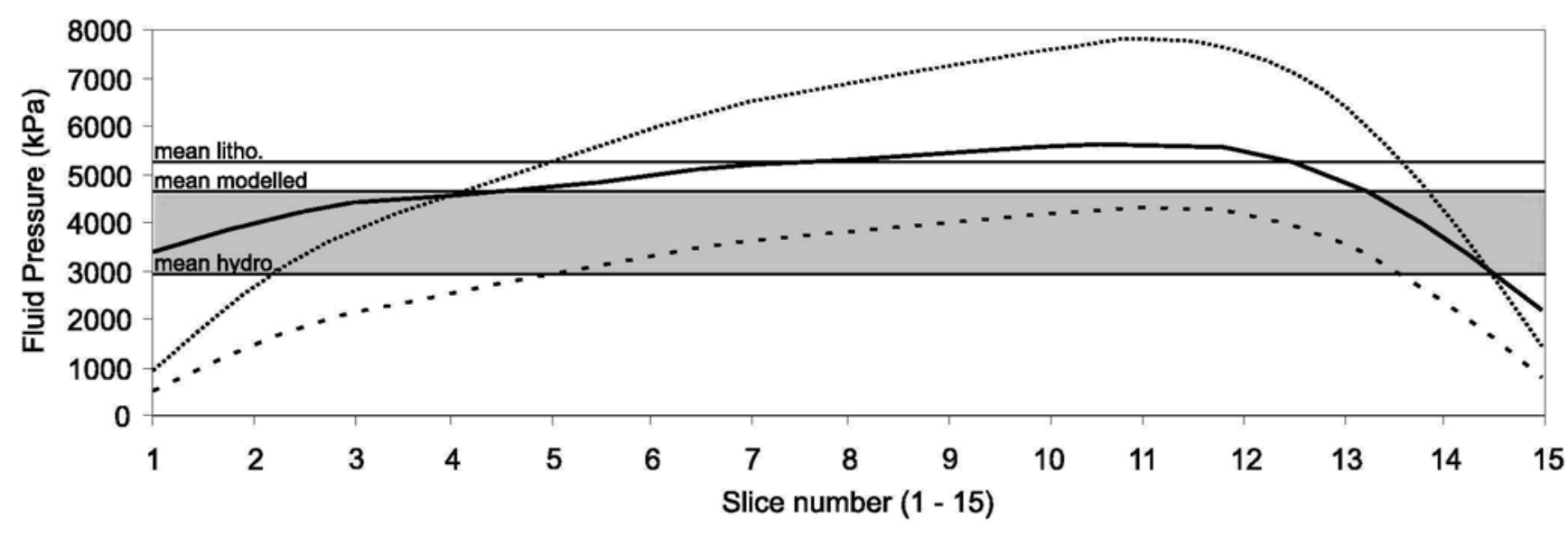

-. - . hydrostatic

modelled

lithostatic

Fig. 6 Graph showing the pore fluid pressure on each slice base (1-15) that was required to destabilise non-circular surface 1 under the gas law based modelling method (heavy line). Excess pore fluid pressure (EPP) distribution was modelled along the entire slip surface (the second method of modelling EPP distribution). Hydrostatic fluid pressure (coarsely broken line) and lithostatic fluid pressure (finely broken line) resolved at each slice base are shown for comparison. Fine horizontal lines show average fluid pressures (hydrostatic, modelled, and lithostatic) along the entire slip surface. The shaded region shows the average modelled EPP for the entire slip surface, c. $1700 \mathrm{kPa}$.

the BSR and therefore modelled with EPP. The non-circular slip surfaces were able to closely follow the BSR all the way down to the return shears, whereas the circular surfaces deviate from the BSR as they maintain perfect arcs (Fig. 4B,C). The stability of the non-circular and circular surfaces, with respect to increasing pore fluid factor, is shown in Fig. 5. Non-circular surface 1 was the least stable of the modelled surfaces.

Figure 6 displays the results of modelling EPP on noncircular surface 1 with respect to the ideal gas law. For this case, EPP distribution was modelled over the entire slip surface (the second modelling scenario). Although the average fluid pressure required to destabilise the slope is lower than lithostatic, unrealistically high pressures are required around the head of the feature (slices 1-3) and also at the toe (slice 15). However, the basal pore fluid pressure required on all other slices is lower than lithostatic. The best estimate for an average amount of EPP (along the BSR) responsible for failure of non-circular surface 1 was c. $1700 \mathrm{kPa}$ (the value required to reduce the factor of safety to 1 ). This value corresponds to the average amount of pore fluid pressure (along the proposed slip surface) in excess of hydrostatic fluid pressure. It is depicted by the shaded region in Fig. 6 .

\section{DISCUSSION}

The simple modelling techniques applied in this study provide a means to quantify an EPP regime responsible for failure of a pre-defined slope geometry. The modelling ignores all other possible loading phenomena, such as seismic loading and storm wave loading, and presumes that the mass above the failure surface behaves perfectly elastically. Non-circular surface 1 is our preferred model, with pore fluid pressure modelled along the entire slip surface with respect to the ideal gas law (results displayed in Fig. 6). The pore pressures calculated around the head of the presumed failure surface (in particular) are very high, but along most of the surface the pressures calculated are well below lithostatic (Fig. 6).

A true evaluation of the effect of free gas liberation (in response to gas hydrate dissociation at the base of the hydrate stability zone) on slope stability, would require consideration of the combined effects of excess pore pressure generation and excess pore pressure dissipation. The amount of methane gas that can be trapped beneath the base of gas hydrate stability, contributing to elevation of the local pore fluid pressure regime, depends not only on the flux of free gas from hydrate dissociation, but also on the rate at which the free gas can be dissipated ("bled off"). The sustainability of the free gas depends on the permeability of the overlying sediments, which is in turn dependent not only on the hydrological characteristics of the material, but also on the concentration of gas hydrate. This is because gas hydrate has the ability both to affect the bulk physical properties of the sediment matrix, and to close off permeability (either primary or secondary) by cementing flow paths as it forms (Kleinberg et al. 2003). Xu \& Germanovich (2006) demonstrated that the magnitude of EPP generated is proportional to (1) the rate of hydrate dissociation and (2) the depth below the seafloor, while it is inversely proportional to (1) sediment permeability and (2) depth below sea level. Their modelling reveals that if permeability is not too low $\left(\geq 10^{-16} \mathrm{~m}^{2}\right)$, the magnitude of EPP generated is typically moderate and insufficient to be the sole trigger of a slope failure. If permeability is significantly lower $\left(\leq 10^{-18} \mathrm{~m}^{2}\right)$, or if sediment pores have a pre-existing overpressure, or both, EPP generation by hydrate dissociation may be capable of being the sole trigger.

We have no control on sediment permeability in this study, and permeability-porosity relationships determined from other convergent margins (e.g., the Gulf of Mexico, the Barbados accretionary wedge, and the Nankai accretionary wedge: Bryant et al. 1975; Bekins et al. 1995; Saffer \& Bekins 1998) vary over several orders of magnitude. However, typical permeabilities from these margins range from $10^{-16} \mathrm{~m}^{2}$ to 
$10^{-19} \mathrm{~m}^{2}$, depending on porosity (Saffer \& Bekins 1998). Our lack of permeability data prevented evaluation of the likely contribution of hydrate dissociation to EPP generation. EPP generation by hydrate dissociation may just have been a loading factor, with an external trigger (such as an earthquake) ultimately reducing the slope's factor of safety to below 1 .

A significant simplification of our modelling was the assumption of 2D slide propagation parallel to the direction of the seismic line. Another simplification arose from the need to adopt typical sediment strength parameters. An ideal slope stability analysis would depend on better geophysical imaging of the slope failure in three dimensions as well as in situ geotechnical parameters, including both strength data and permeability data. An evaluation of the balance between excess pore pressure generation and dissipation from below the zone of gas hydrate stability could then be included in a more detailed finite element slope stability method.

\section{CONCLUSIONS}

Reprocessed seismic data from offshore Fiordland reveal a significant submarine slope failure. The failure is interpreted from a seafloor depression at the point where the BSR converges with it, and from disrupted sediments near where the slope of the seafloor flattens out to subhorizontal.

The association with the gas hydrate stability zone (in particular the base of hydrate stability, marked by the BSR) provided the basis for simple slope stability modelling of excess pore fluid pressure (EPP) on pre-proposed failure surfaces. The simplified assumption, that the slope failure was solely attributable to EPP generation in response to an upward shift in the GHSZ, was modelled with limit equilibrium techniques. Both circular and non-circular methods were employed with interpolated mid-range geotechnical parameters to develop an understanding of the fluid pressure regime required to destabilise a pre-defined slope geometry in the absence of any other loading phenomenon. Non-circular approximations of the failure surface geometry were less stable than circular approximations when EPP was modelled only on slice bases in close proximity to the BSR. Our best model employed the ideal gas law to predict EPP along the entire length of noncircular surface 1 . The best estimate of average EPP required to initiate failure under these conditions was c. $1700 \mathrm{kPa}$. The actual contribution of hydrate dissociation to EPP generation in this region cannot be constrained without permeability data.

\section{ACKNOWLEDGMENTS}

Data for this research have been provided by the New Zealand Ministry of Economic Development and GNS Science. Seismic processing made use of an academic licence for Globe Claritas. Limit-equilibrium modelling was carried out with TSLOPE, a software package produced by Tagasoft (http://www.tagasoft.com). The authors gratefully acknowledge the assistance of Richard Norris for modelling advice, Phaedra Upton for valuable discussions and review of an earlier version of this work, and insightful critiques of the manuscript by Stuart Henrys and an anonymous reviewer. We also thank Phil Barnes and NIWA for access to detailed bathymetric data.

\section{REFERENCES}

Barnes G 2000. Soil mechanics: principles and practice. 2nd ed. Great Britain, Palgrave.

Bekins BA, McCaffrey AM, Dreiss SJ 1995. Episodic and constant flow models for the origin of low-chloride waters in a modern accretionary complex. Water Resources Research 31(12): $3205-3215$.

Bishop AW 1955. The use of the slip circle in the stability analysis of slopes. Geotechnique 5(1): 7-17.

Bouriak S, Vanneste M, Saoutkine A 2000. Inferred gas hydrates and clay diapirs near the Storegga Slide on the southern edge of the Vøring Plateau, offshore Norway. Marine Geology 163: 125-148.

Bryant WR, Hottman W, Trabant P 1975. Permeability of unconsolidated and consolidated marine sediments, Gulf of Mexico. Marine Geotechnology 1: 1-14.

Buffett BA 2000. Clathrate hydrates. Annual Review of Earth and Planetary Sciences 28: 477-507.

Carpenter GB 1981. Coincident sediment slump/clathrate complexes on the U.S. Atlantic slope. Geo-Marine Letters 1: 29-32.

Davey FJ, Smith EGC 1983. The tectonic setting of the Fiordland region, SW New Zealand. Geophysical Journal of the Royal Astronomical Society 72: 23-38.

Delteil J, Collot J-Y, Wood R, Herzer RH, Calmant S, Christoffel D, Coffin MF, Ferrière J, Lamarche G, Lebrun J-F and others 1995. De la faille Alpine à la fosse Puysegur (NouvelleZélande): Résultats de la campagne de cartographie multifaisceaux GEODYNZ-SUD, Leg 2. Comptes Rendus de l'Académie des Sciences, Paris 320(ПIa): 303-309.

Delteil J, Collot J-Y, Wood R, Herzer RH, Calmant S, Christoffel D, Coffin MF, Ferrière J, Lamarche G, Lebrun J-F and others 1996. From strike-slip faulting to oblique subduction: a survey of the Alpine Fault-Puysegur Trench transition, New Zealand. Results of Cruise Geodynz-sud Leg 2. Marine Geophysical Researches 18: 383-399.

Field ME, Barber JHJ 1993. A submarine landslide associated with shallow seafloor gas and gas hydrates off Northern California. In: Schwab WC, Lee HJ, Twichell DC ed. Submarine landslides: selected studies in the U.S. Exclusive Economic Zone. U.S. Geological Survey Bulletin 2002: 151-157.

Fohrmann M, Gorman AR, Pecher IA in press. Seismic characterization of the Fiordland gas hydrate province, New Zealand. In: Collett T, Johnson A, Knapp C, Boswell R ed. Natural gas hydrates: energy resource potential and associated geological hazards. AAPG Special Publication.

Hampton MA, Lee HJ, Locat J 1996. Submarine landslides. Reviews of Geophysics 34(1): 33-59.

Hornbach MJ, Holbrook WS, Gorman AR, Hackwith KL, Lizarralde D, Pecher I 2003. Direct seismic detection of methane hydrate on the Blake Ridge. Geophysics 68(1): 92-100.

Hornbach MJ, Saffer DM, Holbrook WS 2004. Critically pressured free-gas reservoirs below gas-hydrate provinces. Nature 427: 142-144.

Kleinberg RL, Flaum C, Griffin DD, Brewer PG, Malby GE, Peltzer ET, Yesinowski JP 2003. Deep sea NMR: methane hydrate growth habit in porous media and its relationship to hydraulic permeability, deposit accumulation, and submarine slope stability. Journal of Geophysical Research 108(B10): 2508, doi: 10.1029/2003JB002389.

Kvenvolden KA 1988. Methane hydrate-a major reservoir of carbon in the shallow geosphere? Chemical Geology 71: 41-51. 
Lamarche G, Collot J-Y, Wood RA, Sosson M, Sutherland R, Delteil J 1997. The Oligocene-Miocene Pacific-Australia plate boundary, south of New Zealand: evolution from oceanic spreading to strike-slip faulting. Earth and Planetary Science Letters 148: 129-139.

Lebrun J-F, Lamarche G, Collot J-Y, Delteil J 2000. Abrupt strike-slip fault to subduction transition: the Alpine FaultPuysegur Trench connection, New Zealand. Tectonics 19(4): $688-706$.

Lee HJ, Edwards BD 1986. Regional method to assess offshore slope stability. Journal of Geotechnical Engineering 112(5): 489-509.

Lee MW, Hutchinson DR, Collett TS, Dillon WP 1996. Seismic velocities for hydrate-bearing sediments using weighted equation. Journal of Geophysical Research 101: 20347-20358.

Popenoe P, Schmuck EA, Dillon WP 1993. The Cape Fear Landslide: slope failure associated with salt diapirism and gas hydrate decomposition. In: Schwab WC, Lee HJ, Twichell DC ed. Submarine landslides: selected studies in the U.S. Exclusive Economic Zone. U.S. Geological Survey Bulletin 2002: 40-53.

Saffer DM, Bekins BA 1998. Episodic fluid flow in the Nankai accretionary complex: timescale, geochemistry, flow rates, and fluid budget. Journal of Geophysical Research 103(B12): 30351-30370.

Schwab WC, Lee HJ 1988. Causes of two slope-failure types in continental-shelf sediment, northeastern Gulf of Alaska. Journal of Sedimentary Research 58(1): 1-11.
Screaton EJ, Saffer DM 2005. Fluid expulsion and overpressure development during initial subduction at the Costa Rica convergent margin. Earth and Planetary Science Letters 233: $361-374$.

Spencer E 1967. A method of analysis of the stability of embankments assuming parallel inter-slice forces. Geotechnique 17(1): 11-26.

Sutherland R 1995. The Australia-Pacific boundary and Cenozoic plate motions in the southwest Pacific: some constraints from GEOSAT data. Tectonics 14: 819-831.

Townend J 1997. Estimates of conductive heat flow through bottomsimulating reflectors on the Hikurangi and southwest Fiordland continental margins, New Zealand. Marine Geology 141: 209-220.

Tréhu AM, Lin G, Maxwell E, Goldfinger C 1995. A seismic reflection profile across the Cascadia subduction zone offshore central Oregon: new constraints on methane distribution and crustal structure. Journal of Geophysical Research 100(B8): 15101-15116.

Wood R, Herzer R, Sutherland R, Melhuish A 2000. CretaceousTertiary tectonic history of the Fiordland margin, New Zealand. New Zealand Journal of Geology and Geophysics 43: 289-302.

Xu W, Germanovich LN 2006. Excess pore pressure resulting from methane hydrate dissociation in marine sediments: a theoretical approach. Journal of Geophysical Research 111(B1): 1-12. 